Canadian

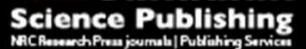

Canadian Journal of Civil Engineering Revue canadienne de génie civil

\title{
Bayesian Model Averaging for the Prediction of Water Main Failure for Small to Large Canadian Municipalities
}

\begin{tabular}{|r|l|}
\hline Journal: & Canadian Journal of Civil Engineering \\
\hline Manuscript ID & cjce-2015-0374.R1 \\
\hline Manuscript Type: & Article \\
\hline Date Submitted by the Author: & 03-Dec-2015 \\
\hline Keyword: List of Authors: & $\begin{array}{l}\text { Kabir, Golam; The University of British Columbia (UBC), School of } \\
\text { Engineering } \\
\text { Tesfamariam, Solomon; The University of British Columbia, School of } \\
\text { Engineering; } \\
\text { Sadiq, Rehan; University of British Columbia Okanagan, }\end{array}$ \\
\hline & \begin{tabular}{l} 
Water main failure, Bayesian model averaging (BMA), regression model, \\
\hline
\end{tabular} \\
\hline
\end{tabular}

SCHOLARONE $^{\text {m }}$

Manuscripts 


\title{
Bayesian Model Averaging for the Prediction of Water Main Failure for Small to Large Canadian Municipalities
}

\author{
Golam Kabir* \\ PhD Candidate \\ School of Engineering \\ University of British Columbia (UBC) \\ 3333 University Way, Kelowna, BC, Canada, V1V1V7 \\ golam.kabir@ubc.ca, Phone: 12508620733 \\ * Corresponding author
}

Dr. Solomon Tesfamariam

Associate Professor

School of Engineering

University of British Columbia (UBC)

3333 University Way, Kelowna, BC, Canada, V1V1V7

solomon.tesfamariam@ubc.ca

Dr. Rehan Sadiq

Professor

School of Engineering

University of British Columbia (UBC)

3333 University Way, Kelowna, BC, Canada, V1V1V7

rehan.sadiq@ubc.ca 


\title{
Bayesian Model Averaging for the Prediction of Water Main Failure for Small to Large Canadian Municipalities
}

\begin{abstract}
Water utilities often rely on water main failure prediction model for developing preventive or proactive repair and replacement action program. Due to inherent uncertainties in modeling, it is challenging to understand the water main failure processes and to predict the failure effectively. In this study, Bayesian model averaging (BMA) method is presented to identify the influential covariates and to predict the failure rates of water mains considering model uncertainties. To accredit the proposed model, it is implemented to predict the failure of pipes of the water distribution network of the City of Kelowna, BC and Greater Vernon Water, BC, Canada. Results indicate that the proposed BMA approach capture the effect of the potential explanatory variables more effectively through the posterior probabilities in contrast to that of the $p$-value given by the classical regression analysis. Moreover, BMA approach perform better compare to classical regression analysis when limited pipe failure data is available.
\end{abstract}

\section{KEYWORDS}

Water main failure, Bayesian model averaging (BMA), regression model, model uncertainty, decision making 


\section{INTRODUCTION}

Utility managers and other authorities need access to location-specific information on pipe failure in order to successfully implement long- and short-term preventive management plans (Mailhot et al. 2000; Asnaashari et al. 2009). Statistical models attempting to predict the failure behaviour of water mains are not only affected both by the quality and quantity of available failure data, but also by the adopted statistical techniques (Kleiner and Rajani 2001, 2002; Pelletier et al. 2003). It is often challenging to develop statistical models for water main failures due to multiple factors affecting these failure and data scarcity (Wood and Lence 2009; Yamijala et al. 2009; Christodoulou 2011). However, substantial efforts have been made to develop pipe failure prediction models using linear and exponential regression methods. Different researchers applied different regression methods like exponential regression (Shamir and Howard 1979; Walski and Pelliccia 1982; Goulter and Kazemi 1988; Kleiner and Rajani 1999), multiple linear regression (Clark et al. 1982; Asnaashari et al. 2009; Wang et al. 2009; Yamijala et al. 2009), multivariate exponential regression (Clark et al. 1982; Rajani and Kleiner 2001; Kleiner and Rajani 2002; Yamijala et al. 2009), linear regression (Kettler and Goulter 1985; Jacobs and Karney 1994), Poisson regression (Boxall et al. 2007; Asnaashari et al. 2009; Christodoulou 2011), generalised linear model (Yamijala et al. 2009; Bubtiena et al. 2011), and logistic generalised linear model (Yamijala et al. 2009). To develop water main failure models, researchers considered different pipe specific, site specific, and environmental factors, and divide or grouped the data according to the material (Boxall et al. 2007; Asnaashari et al. 2009; Wang et al. 2009), number of previous breaks (Pelletier et al. 2003), diameter (Wood and Lence 2009), and installation year (Mailhot et al. 2000). 
To develop an effective regression based water main failure prediction model, uncertainties become an integral part due to incomplete and partial information, integration of data/information from different sources, involvement of human (expert) judgment for the interpretation of data and observations, involvement of multiple expert with different levels of credibility about their knowledge (Rajani and Tesfamariam 2004, 2007; Tesfamariam et al. 2006, 2010; Wood and Lence 2009; Kabir et al. 2015a). In addition, the amount and quality of water main break data available for developing or implementing these regression based models varies among utilities (Wood and Lence 2009). Specially, for the small and medium sized utilities, the uncertainties become a vital and inevitable element of the decision making process due to scarcity of data/information, lack of technical and financial resources, and involvement of human (expert) judgment with limited experience for the interpretation of data and observations (Wood and Lence 2009; Haider et al. 2014). Many utilities are not confident in the data they have and for this, data quality also become a serious issue as many data sets contain uncertainty, e.g. due to unreliable recording of failure times or inaccurate measurements or even the lack of the actual failure times (Economou et al. 2008; Wood and Lence 2009). For this, to improve our understanding of failure processes, accurate quantification of model uncertainties in prediction is necessary.

However, very few regression based water main failure prediction studies mention any preliminary covariate or model selection method that considers these uncertainties. In the linear and exponential regression models, the regression parameters are consider fixed, and leastsquares estimation or maximum likelihood methods are utilized to determine the regression parameters or coefficients (Kleiner and Rajani 2002; Boxall et al. 2007; Asnaashari et al. 2009). Inference was carried out conditionally on the selected "best" model, but this ignores the model 
uncertainty implicit in the variable selection process (Leamer 1978; Raftery et al. 1997; Viallefont et al. 2001). As a consequence, uncertainty about quantities of interest can be underestimated (Raftery et al. 1997; Hoeting et al. 1999; Viallefont et al. 2001). A Bayesian model averaging based model can deal this problem by averaging over all possible models (i.e., combinations of predictors) when making inferences about quantities of interest (Raftery et al. 1997; Viallefont et al. 2001).

The objective of this study is thus to develop a Bayesian Model Averaging (BMA) based water main failure prediction model formally taking uncertainties into consideration. BMA based water main failure prediction model also provides uncertainty assessment. These model uncertainties could be integrated into the analysis in order to see their impact on the decisionmaking process. The proposed model will improve the predictive capability of pipe failure models, and will further assist the utility authorities to proactively address the failures of water mains. Effectiveness of the proposed model is illustrated with the City of Kelowna and Greater Vernon Water pipe failure data.

\section{METHODOLOGY}

The framework of the proposed model is shown in Figure 1. The first step entails gathering pipe characteristics data, soil information and pipe breakage data from the water utility's Geographic Information System (GIS) or database. In the next step, the influential and significant covariates will be selected and water mains failure prediction model will be developed using BMA. Finally, the performance of the model will be evaluated using mean square error (MSE), mean absolute error (MAE), root mean square error (RMSE), and percent bias (PBIAS). The following subsections discuss BMA and model evaluation methods.

Figure 1: Proposed model framework 


\subsection{Bayesian model averaging (BMA)}

In the linear multiple regression problem, the variation in a response variable $y$ is described in terms of $a$ predictor variables $x_{1}, \ldots, x_{a}$. The mean value of $y_{i}$, the response for the $i^{\text {th }}$ individual, can be expressed as:

$$
E\left(y_{i} \mid \beta, X\right)=\beta_{1} x_{i 1}+\beta_{2} x_{i 2}+\cdots+\beta_{a} x_{i a}=x_{i} \beta, i=1,2, \ldots, n
$$

where $x_{i}=\left(x_{i 1}, \ldots, x_{i a}\right)=$ row vector of predictor values for the $i^{\text {th }}$ individual and $\beta=\left(\beta_{1}, \ldots, \beta_{a}\right)=$ column vector of unknown regression parameters or coefficients (Albert 2009; Carlin and Louis 2009). The $\left\{y_{i}\right\}$ are assumed to be conditionally independent given the predictor variables and values of the parameters (Bolstad 2007; Albert 2009). Equal variances are assumed in the normal linear regression, where $\operatorname{var}\left(y_{i} \mid \theta, X\right)=\sigma^{2}$.

Let $\theta=\left(\beta_{1}, \ldots, \beta_{a}, \sigma^{2}\right)$ indicates the vector of unknown parameters. The errors $\varepsilon_{i}=y_{i}$ $E\left(y_{i} \mid \beta, X\right)$ are assumed to be independent and normally distributed with mean 0 and variance $\sigma^{2}$ (Bolstad 2007; Albert 2009; Carlin and Louis 2009). In classical regression analysis, inference will be performed based on the single "best" model which can underestimate the quantity if interest. This problem can be solved by averaging over all possible combinations of predictors when making inferences about quantities of interest (Raftery et al. 1997; Wasserman 2000).

BMA is an average of the posterior distributions under each model weighted by the corresponding posterior model probabilities (Leamer 1978; Wasserman 2000). If $M=\left\{M_{1}, \ldots\right.$, $M_{K}$ \} denotes the set of all models being considered and if $\Delta$ is the quantity of interest, then the posterior distribution of $\Delta$ given the data $D$ is (Raftery et al. 1997; Wasserman 2000)

$$
\operatorname{Pr}(\Delta \mid D)=\sum_{k=1}^{K} \operatorname{Pr}\left(\Delta \mid M_{k}, D\right) \operatorname{Pr}\left(M_{k} \mid D\right)
$$


The posterior probability of model $M_{K}$ is given by (Leamer 1978; Raftery et al. 1997)

$$
\operatorname{Pr}\left(M_{k} \mid D\right)=\frac{\operatorname{Pr}\left(D \mid M_{k}\right) \operatorname{Pr}\left(M_{k}\right)}{\sum_{l=1}^{K} \operatorname{Pr}\left(D \mid M_{l}\right) \operatorname{Pr}\left(M_{l}\right)}
$$

where $\operatorname{Pr}\left(D \mid M_{k}\right)$ is the marginal likelihood of model $M_{k}$, and is computed as:

$$
\operatorname{Pr}\left(D \mid M_{k}\right)=\int \operatorname{Pr}\left(D \mid \theta_{k}, M_{k}\right) \operatorname{Pr}\left(\theta_{k} \mid M_{k}\right) d \theta_{k}
$$

$\theta_{k}$ is the vector of parameters of model $M_{k}, \operatorname{Pr}\left(\mathrm{D} \mid \theta_{k}, M_{k}\right)$ is the likelihood, $\operatorname{Pr}\left(\theta_{k} \mid M_{k}\right)$ is the prior density of $\theta_{k}$ under model $M_{k}$, and $\operatorname{Pr}\left(M_{k}\right)$ is the prior probability that $M_{k}$ is the true model (Raftery et al. 1997; Hoeting et al. 1999).

Averaging over all of the models in this fashion provides better predictive ability than using any single model $M_{j}$ which can measured by a logarithmic scoring rule:

$$
-E\left[\log \left\{\sum_{k=1}^{K} \operatorname{Pr}\left(\Delta \mid M_{k}, D\right) \operatorname{Pr}\left(M_{k} \mid D\right)\right\}\right] \leq-E\left[\log \left\{\operatorname{Pr}\left(\Delta \mid M_{j}, D\right)\right\}\right] \quad(j=1, \ldots, K),
$$

where $\Delta$ is the observable to be predicted and the expectation is with respect to $\sum_{k=1}^{K} \operatorname{Pr}\left(\Delta \mid M_{k}, D\right) \operatorname{Pr}\left(M_{k} \mid D\right)($ Raftery et al. 1997; Hoeting et al. 1999).

\subsection{Model Evaluation}

The overall match between observed and predicted values was assessed using MSE, MAE, RMSE, and PBIAS as shown in Equations 6-9.

$$
\begin{gathered}
M S E=\frac{\sum_{i=1}^{n}\left(O_{i}-P_{i}\right)^{2}}{n} \\
M A E=\frac{\sum_{i=1}^{n}\left|O_{i}-P_{i}\right|}{n} \\
R M S E=\sqrt{\frac{\sum_{i=1}^{n}\left(O_{i}-P_{i}\right)^{2}}{n}}
\end{gathered}
$$




$$
P B I A S=\frac{\sum_{i=1}^{n}\left(O_{i}-P_{i}\right)}{\sum_{i=1}^{n}\left(O_{i}\right)} \times 100
$$

where $O, P$, and $n$ are the observed value, predicted value, and number of observation respectively. MSE (Kleiner and Rajani 1999; Yamijala et al. 2009; Bubtiena et al. 2011; Shafie and Noureldin 2011; El-Shafie et al. 2012; Kabir et al. 2015b) and RMSE (El-Shafie et al. 2006; Shafie and Noureldin 2011; Afan et al. 2014; Kabir et al. 2015b) are the most commonly used performance measures in water main failure modeling. MAE is a common measure to compare the match between estimated and observed values (El-Shafie et al. 2012; Afan et al. 2014). PBIAS measures whether the average tendency of predicted or estimated values is smaller or larger than their observed values (Wood and Lence 2009). Values of PBIAS equal to positive, negative or zero indicate overestimation, underestimation and ideal estimation respectively.

\section{CASE STUDIES}

The proposed BMA methodology is applied on the water distribution network of the City of Kelowna and Greater Vernon Water. The determination of appropriate factors causing pipe failures is vital for an effective water mains failure prediction model development. A variety of factors causing failures have been reported in literature. However, there is no disagreement in the literature about the influence of age in pipe breaks (for example: Shamir and Howard 1979; Clark et al. 1982; Asnaashari et al. 2009). Some researchers observed a linear (Kettler and Goulter 1985; Hu and Hubble 2007) and non-linear relationship (Goulter and Kazemi 1988; Kleiner and Rajani 2001; Boxall et al. 2007) between pipe breaks and age. Pipe diameter is also considered as one of the most influential parameters for pipe breaks (Kettler and Goulter 1985; Yamijala et al. 2009; Christodoulou 2011). Different researchers like Kettler and Goulter (1985), Boxall et al. (2007), $\mathrm{Hu}$ and Hubble (2007) reported an inverse relationship between the pipe 
failure rate and the diameter. Pipe length has been found to contribute significantly to the number of breaks observed (Jacobs and Karney 1994; Asnaashari et al. 2009; Wang et al. 2009; Bubtiena et al. 2011). The number of pipe breaks increases considerably with the length of the pipes is observed in different studies.

Several researchers observed the effects of soil resistivity and corrosivity on the breakage rate of water mains (Boxall et al. 2007; Wood and Lence 2009; Yamijala et al. 2009). Soil resistivity measures how strongly a soil opposes to pass the flow of electric current (AWWA 1999). Soil resistivity significantly affect the deterioration or corrosion of metallic pipes. High soil resistivity will result in a lower corrosion rate probability, while low resistivity results in a higher corrosion rate and failure rate probability (Sadiq et al. 2005). The metallic pipe corrosion process is predominantly facilitated for the corrosive nature of soil environment (Hubell 2003). For metallic pipes, soil corrosivity mainly affected by soil resistivity, redox potential, soil $\mathrm{pH}$, soil moisture content, and sulphide content (AWWA 1999; Sadiq et al. 2005). The probability of external corrosion and hence the failure rates of metallic pipes increases with the increase of soil corrosivity index (Hubell 2003; Sadiq et al. 2004). As the data for only these five parameters are common in the City of Kelowna and Greater Vernon Water, they are considered for further analysis.

\subsection{City of Kelowna, BC}

The City of Kelowna (CoK) is located in British Columbia, Canada and serves more than 50,000 residential consumers and 1,700 industrial, commercial, and institutional properties. The CoK water distribution network consists of $403.4 \mathrm{~km}$ length of pipe with a total of 2,598 individual pipes. The CoK water network comprises of $11.00 \%$ metallic (cast iron (CI), ductile iron (DI), 
copper, steel, and galvanized), 33.95\% cementitious (asbestos (AC) and concrete), and 55.05\% plastic pipes, which include polyvinyl chloride (PVC) and high-density polyethylene (HDPE). The metallic, cementitious, and plastic pipes are installed during 1939-2009, 1939-2010, and 1963-2010 respectively.

The database contains 199 pipe breaks where the first break record obtained for the cementitious, metallic, and plastic pipes in the year 1976, 1977, and 1993 respectively. The majority breaks occurred in $\mathrm{AC}(65.83 \%)$ and $\mathrm{CI}(27.14 \%)$ pipes whereas very few breaks found for plastic $(7.03 \%)$ pipes. It has been found that 99 cementitious pipes experienced breaks whereas 35 metallic, and 11 plastic pipes breaks from 1976-2013. Among all the breaks in AC pipes, almost half of the breaks $(48.48 \%)$ occurred in the pipes having diameter $\leq 150 \mathrm{~mm}$. For this, four groups are considered for the analysis (i.e., metallic, cementitious (diameter $\leq 150 \mathrm{~mm}$ and diameter $>150 \mathrm{~mm}$ ), and Plastic) (Kabir et al. 2015a). Pipe characteristics data like age (year), diameter $(\mathrm{mm})$, length $(\mathrm{m})$, soil resistivity $(\Omega-\mathrm{cm})$, and soil corrosivity index are collected from GIS database of the CoK. The variables used to represent input data together with summary statistics of these data are given in Table 1.

Table 1: Summary of control variables for $\mathrm{CoK}$

For 5 explanatory variables, the initial number of possible models with no interactions will be equal to $2^{5}$ (32) allowing each of the explanatory variables to be either in or out of the model. The model uncertainties arise as it is not known in advance which of these the best model among the 32 models is. BMA propagates this uncertainty through to inference about the five explanatory variables in the same way as the Bayesian approach propagates any other form of uncertainty (Viallefont et al. 2001). As 32 models are quite large, they are reduced into 12 
models. For this, Occam's window approximation (Madigan and Raftery 1994) was used, which follow three steps:

1. calculate the posterior probabilities of all possible models using a workable fast approximation,

2. identify the 'best' model $M_{m}$ or the model with the highest posterior probability, and

3. eliminate the models that are unlikely a posteriori or the models that are more than $\chi$ times less probable than the best one $\left(M_{m}\right)$.

Specifically, Occam's window approximation retain the models $M_{n}$ that satisfy

$$
\frac{P\left(M_{m} \mid D\right)}{P\left(M_{n} \mid D\right)}<\chi
$$

The leaps and bounds algorithm was used to identify the most likely models a posteriori instead of avoiding the calculation of the posterior probabilities of all the models (Volinsky et al. 1997; Hoeting et al. 1999). To eliminate models whose posterior probabilities are much smaller than that of the best model, Bayesian information criterion (BIC) approximation to the Bayes factor and a threshold window for $\chi=20$ was used.

Table 2: Classical and Bayesian analysis of the CoK

Table 2 shows the posterior means $(\mathrm{E}(\beta \mid \mathrm{D}))$, posterior standard deviations $(\mathrm{SD}(\beta \mid \mathrm{D}))$, and posterior probabilities $\left(\operatorname{Pr}\left(\beta_{\mathrm{i}} \neq 0 \mid \mathrm{D}\right)\right)$ of the regression coefficients using the BMA approach for the CoK. The estimated values $(\hat{\beta})$, standard errors (SE) and $p$-values of the regression coefficients for the classical analysis for the CoK are also presented in Table 2. Table 2 also indicates the significant parameters for different models. The variables that were 'not significant' in the classical regression analysis generally had posterior probabilities below 50 per cent 
(Viallefont et al. 2001). Table 2 shows that pipe length is the only significant parameter for metallic pipes whereas pipe age and length are the most influential parameters for the cementitious pipes (for both diameter $\leq 150 \mathrm{~mm}$ and diameter $>150 \mathrm{~mm}$ ). For the plastic pipes, according to the classical approach, pipe age is the only significant parameter and pipe length is non-significant parameter as $p>0.05$ or 0.0564 . However, according to the BMA approach, pipe length is a significant parameter as the posterior probability is greater than $50 \%$ or $93.40 \%$. Thus the classical regression analysis missed the evidence in the data for an effect of this variable. This high posterior probability indicates that pipe length is an influential candidate for the failure of plastic pipes. Soil resistivity and soil corrosivity index is not significant enough for any group of material or model due to less number of failure data and posterior probabilities are below than $25 \%$. The only other non-significant variable for which the posterior probability approached $50 \%$ was pipe age for metallic pipes (40.0\%). Again, BMA approach gives a more nuanced result than the classical regression approach, not indicating evidence for pipe age but not ruling it out either. If pipe age were an important variable for metallic pipes of $\mathrm{CoK}$, this result would point towards the need for more failure data or information on its possible effect.

Figure 2: Posterior distributions and probabilities of the regression coefficients for plastic pipes

Figure 2 shows the posterior distributions and posterior inclusion probabilities of the regression coefficients for plastic pipes. The Figure 2 also indicates the means and standard deviation of the regression coefficients. As the posterior inclusion probabilities of pipe age and length are greater than $50 \%$, they are considered as significant parameters for the failure of plastic pipes of CoK. 
Table 3: Performance of BMA and regression models for the CoK

The comparison results of BMA and regression models for different pipe strata of the CoK are presented in Table 3. According to the Table 3, for all type of pipe strata, the MSE, MAE, and RMSE of the BMA models are lower compare to the regression models. Moreover, due to considering the pipe age as a significant parameter in BMA approach, the MSE, MAE, and RMSE of the plastic pipes are much lower compare to regression model and the normal regression model highly underestimate (PBAIS $=-97.80$ ) the failure rate of plastic pipes compare to BMA (PBAIS = -25.00) approach. The underestimation of the failure rates by normal regression model increase with the decrease of number of failure data or information. For this, it can be conclude that the performance of BMA model is much better compared to normal regression model for all type of pipe strata for the CoK.

\subsection{Greater Vernon Water, BC}

The Greater Vernon Water (GVW) is located in British Columbia, Canada. GVW has approximately 695 connections that are farm or agriculture status, 1,450 connections that are commercial, institutional or industrial, and 17,484 connections that are residential. The GVW water distribution network consists a total of 144,119 individual pipes and $666.14 \mathrm{~km}$ length of pipe. The GVW network comprises of $23.46 \%$ metallic (CI, DI, copper, steel, and galvanized), $22.69 \%$ cementitious (AC, concrete cylinder, and concrete), 36.76\% plastic pipes, which include polyethylene (PE), PVC and HDPE, and $17.10 \%$ of unknown material.

The database contains 306 pipe breaks from 1926 to 2009. The majority breaks occurred in CI (35.95\%), DI (19.61\%), and AC (21.57\%) pipes whereas very few breaks found for plastic $(8.17 \%)$ pipes. It has been found that 178 metallic pipes experienced breaks whereas 69 
cementitious, and 25 plastic pipes breaks. Five groups are considered for the analysis (i.e., metallic (diameter $\leq 150 \mathrm{~mm}$ and diameter $>150 \mathrm{~mm}$ ), cementitious (diameter $\leq 150 \mathrm{~mm}$ and diameter $>150 \mathrm{~mm}$ ), and Plastic). Pipe characteristics data like age, diameter, length, soil resistivity, and soil corrosivity index are collected from GIS database of the GVW. Table 4 represents the summary statistics of the variables for the models of GVW.

Table 4: Summary of control variables for GVW

Table 5: Classical and Bayesian analysis of the GVW

The posterior means, posterior standard deviations, and posterior probabilities of the regression coefficients using the BMA approach for the GVW are resented in Table 5. Table 5 also indicate the estimated values, standard errors and $p$-values of the regression coefficients for the classical analysis for the GVW. Table 5 shows that pipe age and length are the most influential parameters for the metallic pipes (for both diameter $\leq 150 \mathrm{~mm}$ and diameter $>$ $150 \mathrm{~mm}$ ). Pipe length is the only significant parameter for cementitious (diameter $>150 \mathrm{~mm}$ ) pipes. For the cementitious (diameter $\leq 150 \mathrm{~mm}$ ), pipe diameter is non-significant parameter as $p$ $>0.05$ or 0.0632 . However, according to the BMA approach, pipe diameter is a significant parameter as the posterior probability is greater than $50 \%$ or $60.35 \%$. Pipe age, diameter, and length are the most significant parameters for plastic pipes. Due to less number of failure data, soil resistivity and soil corrosivity index is not significant enough for any group of material or model.

Table 6: Performance of BMA and regression models for the Greater Vernon Water

Table 6 indicates the comparison results of BMA and regression models for different pipe strata of the Greater Vernon Water. The MSE, MAE, and RMSE of the BMA models are lower 
compare to the regression models for all type of pipe strata. Moreover, the MSE, MAE, and RMSE of the Cementitious (diameter $\leq 150 \mathrm{~mm}$ ) are much lower for BMA approach compare to regression model due to considering the pipe diameter as a significant parameter. The underestimation of normal regression model (PBAIS $=-3.70$ ) is slightly lower compare to the BMA (PBAIS $=-4.30)$ approach for metallic pipes (diameter $\leq 150 \mathrm{~mm})$. Except that, the normal regression model highly underestimate the failure rate of the remaining four models compare to BMA approach. According to the Table 6, the performance of BMA model is much better compared to normal regression model for all type of pipe strata for the Greater Vernon Water.

\section{CONCLUSIONS}

Uncertainty is inherent regardless of quality and quantity of data for the prediction of water main failure. For this, to improve our understanding of water mains' failure processes, accurate quantification of uncertainty is necessary. In this study, Bayesian model averaging based water main failure prediction models is proposed to account model uncertainty as a formal way. The advantages of the proposed BMA based water main failure models are demonstrated by predicting the failure of pipes of the water distribution network of the City of Kelowna, BC, an Greater Vernon water, BC, Canada. Results indicate that BMA provides a transparent statement of the probability that a variable is associated with the water main failure, through the posterior probability $\operatorname{Pr}\left(\beta_{i} \neq 0 \mid D\right)$ in contrast to that of the $p$-value given by the classical analysis. Moreover, the performance of BMA approach is noticeably better compared to classical normal regression model whenever limited pipe failure data or information is available. For limited data or information, the model uncertainty can be reduced and the performance of the BMA model can be improved by considering the expert opinion for eliciting the informative prior information 
of $\beta$ and $\sigma^{2}$ and incorporating into the analysis. Such an approach could be helpful to identify the influential variables, and show better performance in real life study. Results also identified that the impacts of the covariates differ according to material type. However, pipe physical attributes like pipe age, length were found to contribute more to pipe failure when limited data is available. The results from these BMA models could be further integrated with economic assessment model (e.g., life cycle costing) to estimate the costs of inspection, repair, and rehabilitation, and to develop optimal maintenance or replacement plans. The proposed approach can also incorporate the judgement or knowledge of the utility managers or authorities as prior distribution and assess the overall impact.

The proposed study can be strengthen a great deal by integrating it with the GIS system of the water utilities to identify the high breakage rate zone and to develop an effective program of municipalities. To improve the performance of the models, other environmental parameters (e.g., rain deficit, freezing index), hydraulic information (e.g., water velocity, pressure) can be integrated. The proposed model can further investigate with the other sized of water utilities having different demographic and environmental conditions. As a future research, the performance of the proposed model can compare with different types of prediction models like artificial neural network (ANN) (El-Shafie and Noureldin 2011; El-Shafie et al. 2012; Afan et al. 2014), adaptive neuro-fuzzy inference system (ANFIS) (El-Shafie et al. 2006), Bayesian belief network (BBN) (Kabir et al. 2015a). 


\section{ACKNOWLEDGEMENTS}

The financial support through Natural Sciences and Engineering Research Council of Canada (NSERC) Collaborative Research and Development Grant (Number: CRDPJ434629-12) is acknowledged.

\section{REFERENCES}

Afan, H. A., El-Shafie, A., Yaseen, Z. M., Hameed, M. M., Mohtar, W. H. M. W., and Hussain, A. 2015. ANN based sediment prediction model utilizing different input scenarios. Water Resources Management, 29(4): 1231-1245.

Albert, J. 2009. Bayesian Computation with R, 2nd Ed., Springer, New York, 304.

Asnaashari, A., McBean, E., Shahrour, I., and Gharabaghi, B. 2009. Prediction of watermain failure frequencies using multiple and Poisson regression. Water Science \& Technology: Water Supply, 9(1): 9-19.

AWWA. 1999. ANSI/AWWA C105/A21.5. APPENDIX A-Notes on Procedures for Soil Survey Tests and Observation and Their Interpretations to Determine Wether Polyethyline Encasement Should Be Used. Report no., American Water Works Association.

Bolstad, W. 2007. Introduction to Bayesian Statistics, 2nd Ed., Hoboken, NJ: John Wiley and Sons, 464 . 
Boxall, J., O’Hagan, A., Pooladsaz, S., and Saul, A. J. 2007. Estimation of burst rates in water distribution mains. Water management, 160(2): 73-82.

Bubtiena, A.M., ElShafie, A.H., and Jaafar, O. 2011. Performance improvement for pipe breakage prediction modeling using regression method. International Journal of the Physical Sciences, 6(25): 6025-6035.

Carlin, B., and Louis, T. 2009. Bayesian Methods for Data Analysis, $3^{\text {rd }}$ Ed., Boca Roton, FL: Chapman and Hall, 552.

Christodoulou, S.E. 2011. Water Network Assessment and Reliability Analysis by Use of Survival Analysis. Water Resources Management, 25(4): 1229-1238.

Clark, C.M. 1971. Expansive-soil effect on buried pipe. Journal (American Water Works Association), 63: 424-427.

Clark, R., Stafford, C., and Goodrich, J. 1982. Water distribution systems: a spatial and cost evaluation. Journal of the Water Resources Planning and Management Division, 108(WR3): $243-256$.

Economou, T., Kapelan, Z., and Bailey, T.C. 2008. A zero-inflated Bayesian model for the prediction of water pipe bursts. Proceedings of the 10th Annual Water Distribution Systems Analysis Conference (WDSA), Van Zyl, J.E., Ilemobade, A.A., Jacobs, H.E. (eds.), August 17-20, 2008, Kruger National Park, South Africa.

El-Shafie, A., Alsulami, H. M., Jahanbani, H., and Najah, A. 2013. Multi-lead ahead prediction model of reference evapotranspiration utilizing ANN with ensemble procedure. Stochastic Environmental Research and Risk Assessment, 27(6): 1423-1440. 
El-Shafie, A., and Noureldin, A. 2011. Generalized versus non-generalized neural network model for multi-lead inflow forecasting at Aswan High Dam.Hydrology and Earth System Sciences.

El-Shafie, A., Taha, M. R., and Noureldin, A. 2007. A neuro-fuzzy model for inflow forecasting of the Nile river at Aswan high dam. Water resources management, 21(3): 533-556.

Goulter, I.C., and Kazemi, A. 1988. Spatial and temporal groupings of watermain pipe breakage in Winnipeg. Canadian Journal of Civil Engineering, 15(1): 91-97.

Hoeting, J.A., Madigan, D., Raftery, A.E., and Volinsky, C.T. 1999. Bayesian model averaging: a tutorial. Statistical science, 14(4): 382-401.

Haider, H., Sadiq, R., and Tesfamariam, S. 2013. Performance indicators for small-and mediumsized water supply systems: a review. Environmental reviews, 22(1): 1-40.

Hu, Y., and Hubble, D.W. 2007. Factors contributing to the failure of asbestos cement water mains. Canadian Journal of Civil Engineering, 34(5): 608-621.

Hubell. 2003. Corrosion Guide. Helical Screw Foundation System Design Manual for New Construction. http://www.vickars.com/screwpile_manual/PDF_Files/Step7-CorrosionGuide .pdf.

Jacobs P., and Karney, B. 1994. GIS development with application to cast iron water main breakage rates. In Proc. 2nd International Conference on Water Pipeline Systems, Edinburgh. Mechanical Engineering Publication Ltd, London.

Kabir, G., Demissie, G., Sadiq, R., and Tesfamariam, S. 2015a. Integrating failure prediction models for water mains: Bayesian belief network based data fusion. Knowledge-Based Systems, 85: 159-169. 
Kabir, G., Tesfamariam, S., Loeppky, J., and Sadiq, R. 2015b. Integrating Bayesian Linear Regression with Ordered Weighted Averaging: Uncertainty Analysis for Predicting Water Main Failures. ASCE-ASME Journal of Risk and Uncertainty in Engineering Systems, Part A: Civil Engineering, 1(3): 04015007.

Kettler, A., and Goulter, I. 1985. An analysis of pipe breakage in urban water distribution networks. Canadian Journal of Civil Engineering, 12(2): 286- 293.

Kleiner, Y., and Rajani, B. 2002. Forecasting Variations and Trends in Water-Main Breaks. Journal of Infrastructure Systems, 8(4): 122-131.

Kleiner, Y., and Rajani, B. 2001. Comprehensive review of structural deterioration of water mains: statistical models. Urban Water, 3(3): 131-150.

Kleiner, Y., and Rajani, B. 1999. Using limited data to assess future needs. Journal of AWWA, 91(7): 47-62.

Leamer, E.E. 1978. Specification Searches, New York: Wiley.

Madigan, D., and Raftery, A.E. 1994. Model selection and accounting for model uncertainty in graphical models using Occam's window. Journal of the American Statistical Association, 89: $1535-1546$.

Mailhot, A., Pelletier, G., and Noel, J.P.V. 2000. Modeling the evolution of the structural state of water pipe networks with brief recorded pipe break histories: Methodology and application. Water Resources Research, 36(10): 3053-3062.

Pelletier, G., Mailhot, A., and Villeneuve, J.P. 2003. Modeling Water Pipe Breaks-Three Case Studies. Journal of Water Resources Planning and Management, 129(2):115-123.

Raftery, A.E., Madigan, D., and Hoeting, J.A. 1997. Bayesian model averaging for linear regression models. Journal of the American Statistical Association, 92(437): 179-191. 
Rajani, B., and Kleiner, Y. 2001. WARP-water mains renewal planner. In: Proceedings of Int. Conf. on Underground Infrastructure Research, 1-6.

Rajani, B., and Tesfamariam, S. 2007. Estimating time to failure of ageing cast iron water mains under uncertainties. ICE Water Management Journal, 160(2): 83-88.

Rajani, B., and Tesfamariam, S. 2004. Uncoupled axial, flexural, and circumferential pipe-soil interaction analyses of partially supported jointed water mains. Canadian Geotechnical Journal, 41(6): 997-1010.

Sadiq, R., Veitch, B., Husain, T., and Bose, N. 2005. Prioritizing environmental effects monitoring (EEM) programs: a risk-based strategy. In: Armsworthy, S. L., Cranford, P. J. and Lee, K. (eds) Offshore Oil and Gas Environmental Effects Monitoring: Approaches and Technologies. Battelle Press, OH, pp. $95-110$.

Shamir, U., and Howard, C. 1979. Analytic approach to scheduling pipe replacement. Journal of AWWA, 71(5): 248-258.

Tesfamariam, S., Rajani, B., and Sadiq, R. 2006. Consideration of uncertainties to estimate structural capacity of ageing cast iron water mains - a possibilistic approach. Canadian Journal of Civil Engineering, 33(8): 1050-1064.

Tesfamariam, S., Sadiq, R., and Najjaran, H. 2010. Decision making under uncertainty-an example for seismic risk management. Risk Analysis, 30(1): 78-94.

Viallefont, V., Raftery, A.E., and Richardson, S. 2001. Variable selection and Bayesian model averaging in case-control studies. Statistics in medicine, 20(21): 3215-3230.

Walski, T.M., and Pelliccia, A. 1982. Economic analyses of watermain breaks. Journal of AWWA, 74(3): 140-147. 
Wang, Y., Zayed, T., and Moselhi, O. 2009. Prediction models for annual break rates of water mains. Journal of Performance of Constructed Facilities, 23(1): 47-54.

Wasserman, L. 2000. Bayesian model selection and model averaging. Journal of mathematical psychology, 44(1): 92-107.

Wood, A., and Lence, B.J. 2009. Using Water main break data to improve asset management for small and medium utilities: District of Maple Ridge, B.C.. Journal of Infrastructure Systems, 15(2): 111-119.

Yamijala, S., Guikema, S. D., and Brumbelow, K. 2009. Statistical models for the analysis of water distribution system pipe break data. Reliability Engineering \& System Safety, 94(2): 282-293. 


\section{LIST OF TABLES}

Table 1: Summary of control variables for $\mathrm{CoK}$

\begin{tabular}{|c|c|c|c|c|c|c|}
\hline \multirow{2}{*}{ Variable } & \multirow{2}{*}{ Unit } & \multirow{2}{*}{ Scale } & \multirow{2}{*}{ Metallic } & Cementitious & & \multirow{2}{*}{ Plastic } \\
\hline & & & & Dia $\leq 150$ & Dia $>150$ & \\
\hline \multirow{4}{*}{ NBRKS } & \multirow{4}{*}{ NA } & Min & 1.00 & 1.00 & 1.00 & 1.00 \\
\hline & & Max & 5.00 & 4.00 & 4.00 & 3.00 \\
\hline & & Mean & 1.54 & 1.44 & 1.22 & 1.27 \\
\hline & & SD & 1.04 & 0.82 & 0.58 & 0.65 \\
\hline \multirow{4}{*}{ AGE } & \multirow{4}{*}{ Year } & Min & 35.00 & 22.00 & 15.00 & 9.00 \\
\hline & & Max & 66.00 & 57.00 & 59.00 & 28.00 \\
\hline & & Mean & 56.66 & 40.96 & 41.06 & 22.45 \\
\hline & & SD & 8.53 & 6.06 & 6.72 & 5.47 \\
\hline \multirow{4}{*}{ DIA } & \multirow{4}{*}{$\mathrm{mm}$} & Min & 100.00 & 100.00 & 200.00 & 150.00 \\
\hline & & Max & 400.00 & 150.00 & 350.00 & 350.00 \\
\hline & & Mean & 182.86 & 136.46 & 241.18 & 195.45 \\
\hline & & SD & 70.65 & 22.45 & 46.59 & 61.05 \\
\hline \multirow{4}{*}{ LENGTH } & \multirow{4}{*}{$\mathrm{m}$} & Min & 47.25 & 27.39 & 77.78 & 86.10 \\
\hline & & Max & 714.52 & 591.63 & 545.61 & 735.12 \\
\hline & & Mean & 211.23 & 200.08 & 232.39 & 294.22 \\
\hline & & SD & 142.77 & 114.64 & 104.18 & 188.99 \\
\hline \multirow{4}{*}{ RESIS } & \multirow{4}{*}{$\Omega-\mathrm{cm}$} & Min & 1950.00 & 1950.00 & 1950.00 & 1950.00 \\
\hline & & Max & 2750.00 & 10750.00 & 3000.00 & 10750.00 \\
\hline & & Mean & 2292.86 & 3071.88 & 2090.20 & 3718.18 \\
\hline & & SD & 401.68 & 2343.53 & 331.82 & 3003.85 \\
\hline \multirow{4}{*}{ SCI } & \multirow{4}{*}{ NA } & Min & 4.00 & 1.00 & 1.00 & 0.00 \\
\hline & & Max & 12.50 & 5.00 & 5.00 & 5.00 \\
\hline & & Mean & 12.04 & 2.96 & 3.98 & 2.55 \\
\hline & & SD & 1.42 & 1.88 & 1.58 & 1.81 \\
\hline
\end{tabular}

NBRKS: Number of previous breaks, AGE: Pipe age,DIA: Diameter, LENGTH: Length, RESIS: Soil resistivity, SCI: Soil corrosivity index, NA symbolizes that there are no units 
Table 2: Classical and Bayesian analysis of the CoK

\begin{tabular}{|c|c|c|c|c|c|c|c|}
\hline \multirow{2}{*}{ Model } & \multirow{2}{*}{ Variable } & \multicolumn{3}{|c|}{ Classical variable selection } & \multicolumn{3}{|c|}{ Bayesian model averaging } \\
\hline & & $\hat{\beta}$ & SE & $p$-value & $\mathrm{E}(\beta \mid \mathrm{D})$ & $\mathrm{SD}(\beta \mid \mathrm{D})$ & $\operatorname{Pr}\left(\beta_{\mathrm{i}} \neq 0 \mid \mathrm{D}\right)$ \\
\hline \multirow{6}{*}{ Metallic } & Intercept & 0.82124 & 4.66109 & 0.8614 & 2.3043 & NA & $100.00 \% *$ \\
\hline & AGE & -0.02015 & 0.01160 & 0.0931 & -0.0065 & 0.0104 & $40.00 \%$ \\
\hline & DIA & -0.00121 & 0.00135 & 0.3768 & -0.0002 & 0.0008 & $20.30 \%$ \\
\hline & $\log ($ LENGTH $)$ & -0.86505 & 0.15638 & $<0.0001 *$ & -0.8481 & 0.1420 & $100.00 \% *$ \\
\hline & SCI & 0.03141 & 0.07827 & 0.6911 & 0.0017 & 0.0265 & $11.90 \%$ \\
\hline & $\log ($ RESIS $)$ & 0.34164 & 0.53387 & 0.5272 & 0.0617 & 0.2684 & $21.05 \%$ \\
\hline \multirow{6}{*}{$\begin{array}{l}\text { Cement- } \\
\text { itious } \\
(\text { Dia } \leq \\
150)\end{array}$} & Intercept & 3.68387 & 1.36080 & $0.0098^{*}$ & 3.71779 & NA & $100.00 \% *$ \\
\hline & AGE & -0.04691 & 0.01067 & $0.0001 *$ & -0.04720 & 0.01005 & $100.00 \% *$ \\
\hline & DIA & -0.00195 & 0.00377 & 0.6074 & -0.00038 & 0.00139 & $16.40 \%$ \\
\hline & $\log ($ LENGTH $)$ & -0.68677 & 0.11747 & $<0.0001^{*}$ & -0.67596 & 0.11071 & $100.00 \% *$ \\
\hline & SCI & -0.00834 & 0.04926 & 0.8664 & -0.00410 & 0.01661 & $15.45 \%$ \\
\hline & $\log ($ RESIS $)$ & 0.04710 & 0.12630 & 0.71107 & 0.00830 & 0.05023 & $15.80 \%$ \\
\hline \multirow{6}{*}{$\begin{array}{l}\text { Cement- } \\
\text { itious } \\
\text { (Dia } \\
>150 \text { ) }\end{array}$} & Intercept & 0.20290 & 2.91300 & 0.94479 & 2.19677 & NA & $100.00 \% *$ \\
\hline & AGE & -0.02197 & 0.00674 & $0.00213 *$ & -0.02112 & 0.00799 & $95.35 \% *$ \\
\hline & DIA & 0.00010 & 0.00114 & 0.93117 & 0.00002 & 0.00040 & $15.50 \%$ \\
\hline & $\log ($ LENGTH $)$ & -0.76750 & 0.09900 & $<0.0001^{*}$ & -0.75772 & 0.09824 & $100.00 \% *$ \\
\hline & SCI & -0.02027 & 0.03321 & 0.54479 & -0.00471 & 0.01582 & $17.80 \%$ \\
\hline & $\log ($ RESIS $)$ & 0.37340 & 0.34760 & 0.28836 & 0.09540 & 0.23139 & $23.55 \%$ \\
\hline \multirow{6}{*}{ Plastic } & Intercept & 6.14582 & 2.71310 & 0.07290 & 4.68895 & NA & $100.00 \% *$ \\
\hline & AGE & -0.09348 & 0.03197 & $0.03290 *$ & -0.08338 & 0.03718 & $92.77 \% *$ \\
\hline & DIA & -0.00100 & 0.00278 & 0.73380 & -0.00009 & 0.00109 & $17.12 \%$ \\
\hline & $\log ($ LENGTH $)$ & -0.71817 & 0.29055 & 0.05640 & -0.72552 & 0.31025 & $93.48 \% *$ \\
\hline & SCI & 0.00937 & 0.10475 & 0.93220 & 0.00827 & 0.04288 & $18.88 \%$ \\
\hline & $\log$ (RESIS) & -0.17837 & 0.32116 & 0.60250 & -0.04115 & 0.14323 & $21.46 \%$ \\
\hline
\end{tabular}

* Significant variable 
Table 3: Performance of BMA and regression models for the CoK

\begin{tabular}{|l|l|l|l|l|l|}
\hline Error & Model & Metallic & Cementitious (Dia $\leq 150)$ & Cementitious (Dia >150) & Plastic \\
\hline \multirow{3}{*}{ MSE } & BMA & 0.0145 & 0.0091 & 0.0023 & 0.1459 \\
\cline { 2 - 6 } & REG & 0.2151 & 0.2272 & 0.7781 & 1.9111 \\
\hline \multirow{2}{*}{ MAE } & BMA & 0.0751 & 0.0648 & 0.0297 & 0.1506 \\
\cline { 2 - 6 } & REG & 0.3417 & 0.6531 & 0.6457 & 1.4029 \\
\hline \multirow{2}{*}{ RMSE } & BMA & 0.1204 & 0.0956 & 0.0479 & 0.3819 \\
\cline { 2 - 6 } & REG & 0.8466 & 0.4127 & 0.8645 & 1.7817 \\
\hline \multirow{2}{*}{ PBAIS } & BMA & -14.4000 & -6.7000 & -4.9000 & -25.0000 \\
\cline { 2 - 6 } & REG & -25.5000 & -15.1000 & -11.1000 & -97.8000 \\
\hline
\end{tabular}


Table 4: Summary of control variables for GVW

\begin{tabular}{|c|c|c|c|c|c|c|c|}
\hline \multirow{2}{*}{ Variables } & \multirow{2}{*}{ Unit } & \multirow{2}{*}{ Scales } & \multicolumn{2}{|l|}{ Metallic } & \multicolumn{2}{|c|}{ Cementitious } & \multirow{2}{*}{ Plastic } \\
\hline & & & $\mathrm{Dia} \leq 150$ & Dia $>150$ & Dia $\leq 150$ & Dia $>150$ & \\
\hline \multirow{4}{*}{ NBRKS } & \multirow{4}{*}{ NA } & Min & 1.00 & 1.00 & 1.00 & 1.00 & 1.00 \\
\hline & & $\operatorname{Max}$ & 4.00 & 2.00 & 5.00 & 2.00 & 3.00 \\
\hline & & Mean & 1.23 & 1.11 & 1.20 & 1.17 & 1.40 \\
\hline & & SD & 0.55 & 0.32 & 0.69 & 0.38 & 0.71 \\
\hline \multirow{4}{*}{ AGE } & \multirow{4}{*}{ Year } & Min & 17.00 & 6.00 & 36.10 & 35.10 & 4.00 \\
\hline & & Max & 88.00 & 88.00 & 50.10 & 48.00 & 47.00 \\
\hline & & Mean & 50.59 & 42.26 & 43.92 & 45.43 & 22.41 \\
\hline & & SD & 17.95 & 17.94 & 3.45 & 2.97 & 13.49 \\
\hline \multirow{4}{*}{ DIA } & \multirow{4}{*}{$\mathrm{mm}$} & Min & 50.00 & 200.00 & 50.00 & 200.00 & 25.00 \\
\hline & & Max & 150.00 & 600.00 & 150.00 & 900.00 & 300.00 \\
\hline & & Mean & 130.63 & 277.78 & 128.89 & 325.00 & 133.20 \\
\hline & & SD & 29.68 & 106.53 & 27.15 & 197.81 & 68.04 \\
\hline \multirow{4}{*}{ LENGTH } & \multirow{4}{*}{$\mathrm{m}$} & Min & 4.27 & 5.12 & 2.26 & 17.09 & 6.10 \\
\hline & & $\operatorname{Max}$ & 605.67 & 321.05 & 332.69 & 383.17 & 314.44 \\
\hline & & Mean & 84.93 & 101.80 & 101.83 & 136.07 & 110.29 \\
\hline & & SD & 68.08 & 76.10 & 66.17 & 87.47 & 81.30 \\
\hline \multirow{4}{*}{ RESIS } & \multirow{4}{*}{$\Omega-\mathrm{cm}$} & Min & 1000.00 & 1000.00 & 1000.00 & 1250.00 & 1000.00 \\
\hline & & $\operatorname{Max}$ & 2800.00 & 2800.00 & 2800.00 & 2800.00 & 2800.00 \\
\hline & & Mean & 2577.46 & 2287.50 & 2490.00 & 2637.50 & 2442.00 \\
\hline & & SD & 540.54 & 712.98 & 513.41 & 457.37 & 536.90 \\
\hline \multirow{4}{*}{ SCI } & \multirow{4}{*}{ NA } & Min & 0.00 & 0.00 & 0.00 & 0.80 & 0.00 \\
\hline & & $\operatorname{Max}$ & 1.00 & 0.79 & 1.00 & 1.00 & 0.50 \\
\hline & & Mean & 0.08 & 0.17 & 0.80 & 0.83 & 0.02 \\
\hline & & SD & 0.22 & 0.30 & 0.13 & 0.07 & 0.10 \\
\hline
\end{tabular}

NBRKS: Number of previous breaks, AGE: Pipe age,DIA: Diameter, LENGTH: Length, RESIS: Soil resistivity, SCI: Soil corrosivity index, NA symbolizes that there are no units 
Table 5: Classical and Bayesian analysis of the GVW

\begin{tabular}{|c|c|c|c|c|c|c|c|}
\hline \multirow{2}{*}{ Model } & \multirow{2}{*}{ Variable } & \multicolumn{3}{|c|}{ Classical variable selection } & \multicolumn{3}{|c|}{ Bayesian model averaging } \\
\hline & & $\hat{\beta}$ & $\mathrm{SE}$ & $p$-value & $E(\beta \mid D)$ & $\mathrm{SD}(\beta \mid \mathrm{D})$ & $\operatorname{Pr}\left(\beta_{i} \neq 0 \mid D\right)$ \\
\hline \multirow{6}{*}{$\begin{array}{l}\text { Metallic } \\
\text { (Dia } \leq \\
150)\end{array}$} & Intercept & 6.23455 & 1.75817 & $0.00054 *$ & 3.90527 & NA & $100.00 \% *$ \\
\hline & $\mathrm{AGE}$ & -0.01812 & 0.00159 & $<0.0001^{*}$ & -0.01783 & 0.00159 & $100.00 \% *$ \\
\hline & DIA & -0.00067 & 0.00095 & 0.48319 & -0.00007 & 0.00037 & $9.35 \%$ \\
\hline & $\log ($ LENGTH $)$ & -0.95761 & 0.03353 & $<0.0001^{*}$ & -0.94872 & 0.03411 & $100.00 \% *$ \\
\hline & SCI & -0.42841 & 0.29236 & 0.14514 & -0.01560 & 0.08131 & $9.40 \%$ \\
\hline & $\log$ (RESIS) & -0.28009 & 0.22059 & 0.20634 & -0.00324 & 0.05398 & $9.60 \%$ \\
\hline \multirow{6}{*}{$\begin{array}{l}\text { Metallic } \\
\text { (Dia } \\
>150 \text { ) }\end{array}$} & Intercept & 7.13294 & 4.01595 & 0.0859 & 4.33849 & NA & $100.00 \% *$ \\
\hline & AGE & -0.03115 & 0.00324 & $<0.0001^{*}$ & -0.02969 & 0.00364 & $100.00 \% *$ \\
\hline & DIA & -0.00093 & 0.00061 & 0.1387 & -0.00025 & 0.00053 & $29.00 \%$ \\
\hline & $\log ($ LENGTH $)$ & -0.92372 & 0.06948 & $<0.0001^{*}$ & -0.94153 & 0.07280 & $100.00 \% *$ \\
\hline & SCI & -0.49654 & 0.65881 & 0.4569 & -0.03147 & 0.16154 & $17.04 \%$ \\
\hline & $\log$ (RESIS) & -0.32048 & 0.51265 & 0.5366 & 0.01100 & 0.11855 & $16.61 \%$ \\
\hline \multirow{6}{*}{$\begin{array}{l}\text { Cement- } \\
\text { itious } \\
\text { (Dia } \leq \\
150)\end{array}$} & Intercept & 4.96442 & 1.75586 & $0.0074^{*}$ & 3.45109 & NA & $100.00 \% *$ \\
\hline & $\mathrm{AGE}$ & -0.00736 & 0.01430 & 0.6096 & -0.00215 & 0.00802 & $18.05 \%$ \\
\hline & DIA & 0.00354 & 0.00185 & 0.0632 & 0.00244 & 0.00245 & $60.35 \% *$ \\
\hline & $\log ($ LENGTH $)$ & -0.91664 & 0.05609 & $<0.0001^{*}$ & -0.89495 & 0.06023 & $100.00 \% *$ \\
\hline & SCI & 0.07931 & 0.35606 & 0.8249 & 0.01199 & 0.14248 & $13.35 \%$ \\
\hline & $\log$ (RESIS) & -0.29397 & 0.18179 & 0.1139 & -0.11618 & 0.19250 & $36.50 \%$ \\
\hline \multirow{6}{*}{$\begin{array}{l}\text { Cement- } \\
\text { itious } \\
\text { (Dia } \\
>150 \text { ) }\end{array}$} & Intercept & 3.77192 & 2.24511 & 0.1100 & 3.75444 & NA & $100.00 \% *$ \\
\hline & AGE & -0.03094 & 0.02074 & 0.1530 & -0.01348 & 0.02113 & $40.80 \%$ \\
\hline & DIA & -0.00033 & 0.00032 & 0.3110 & -0.00011 & 0.00024 & $29.15 \%$ \\
\hline & $\log ($ LENGTH $)$ & -0.97626 & 0.10895 & $<0.0001 *$ & -0.99670 & 0.10706 & $100.00 \% *$ \\
\hline & SCI & -0.88139 & 0.99988 & 0.3900 & -0.15076 & 0.57838 & $21.60 \%$ \\
\hline & $\log$ (RESIS) & 0.19910 & 0.25734 & 0.4490 & 0.02680 & 0.13112 & $17.60 \%$ \\
\hline \multirow{6}{*}{ Plastic } & Intercept & 4.81012 & 3.41649 & 0.1753 & 5.78553 & NA & $100.00 \% *$ \\
\hline & AGE & -0.06605 & 0.00856 & $<0.0001^{*}$ & -0.06299 & 0.00898 & $100.00 \% *$ \\
\hline & DIA & -0.00486 & 0.00170 & $0.0102 *$ & -0.00442 & 0.00217 & $90.70 \% *$ \\
\hline & $\log ($ LENGTH $)$ & -0.99597 & 0.11365 & $<0.0001^{*}$ & -0.96448 & 0.11805 & $100.00 \% *$ \\
\hline & SCI & 0.16936 & 1.08113 & 0.8772 & 0.02064 & 0.45325 & $15.50 \%$ \\
\hline & $\log ($ RESIS $)$ & 0.20035 & 0.39965 & 0.6219 & 0.04108 & 0.20391 & $17.95 \%$ \\
\hline
\end{tabular}

* Significant variable 
Table 6: Performance of BMA and regression models for the Greater Vernon Water

\begin{tabular}{|l|l|l|l|l|l|l|}
\hline \multirow{2}{*}{ Error } & Model & $\begin{array}{l}\text { Metallic (Dia } \\
\leq 150)\end{array}$ & $\begin{array}{l}\text { Metallic (Dia } \\
>150)\end{array}$ & $\begin{array}{l}\text { Cementitious } \\
(\text { Dia } \leq 150)\end{array}$ & $\begin{array}{l}\text { Cementitious } \\
(\text { Dia }>150)\end{array}$ & Plastic \\
\hline \multirow{2}{*}{ MSE } & BMA & 0.0579 & 0.3325 & 0.0681 & 0.0150 & 4.0741 \\
\cline { 2 - 7 } & REG & 0.1586 & 1.8230 & 0.6260 & 0.0590 & 14.7546 \\
\hline \multirow{2}{*}{ MAE } & BMA & 0.1207 & 0.2220 & 0.0996 & 0.0699 & 0.9972 \\
\cline { 2 - 7 } & REG & 0.2236 & 0.6378 & 0.2793 & 0.1154 & 1.7815 \\
\hline \multirow{2}{*}{ RMSE } & BMA & 0.2407 & 0.5766 & 0.2609 & 0.1226 & 2.0184 \\
\cline { 2 - 7 } & REG & 0.4422 & 1.3502 & 0.7912 & 0.2429 & 3.8412 \\
\hline \multirow{2}{*}{ PBAIS } & BMA & -4.3000 & -11.8000 & -9.0000 & -4.8000 & -19.8000 \\
\cline { 2 - 7 } & REG & -3.7000 & -61.2000 & -48.1000 & -27.1000 & -60.1000 \\
\hline
\end{tabular}




\section{LIST OF FIGURES}

Figure 1: Proposed model framework

Figure 2: Posterior distributions and probabilities of the regression coefficients for plastic pipes 


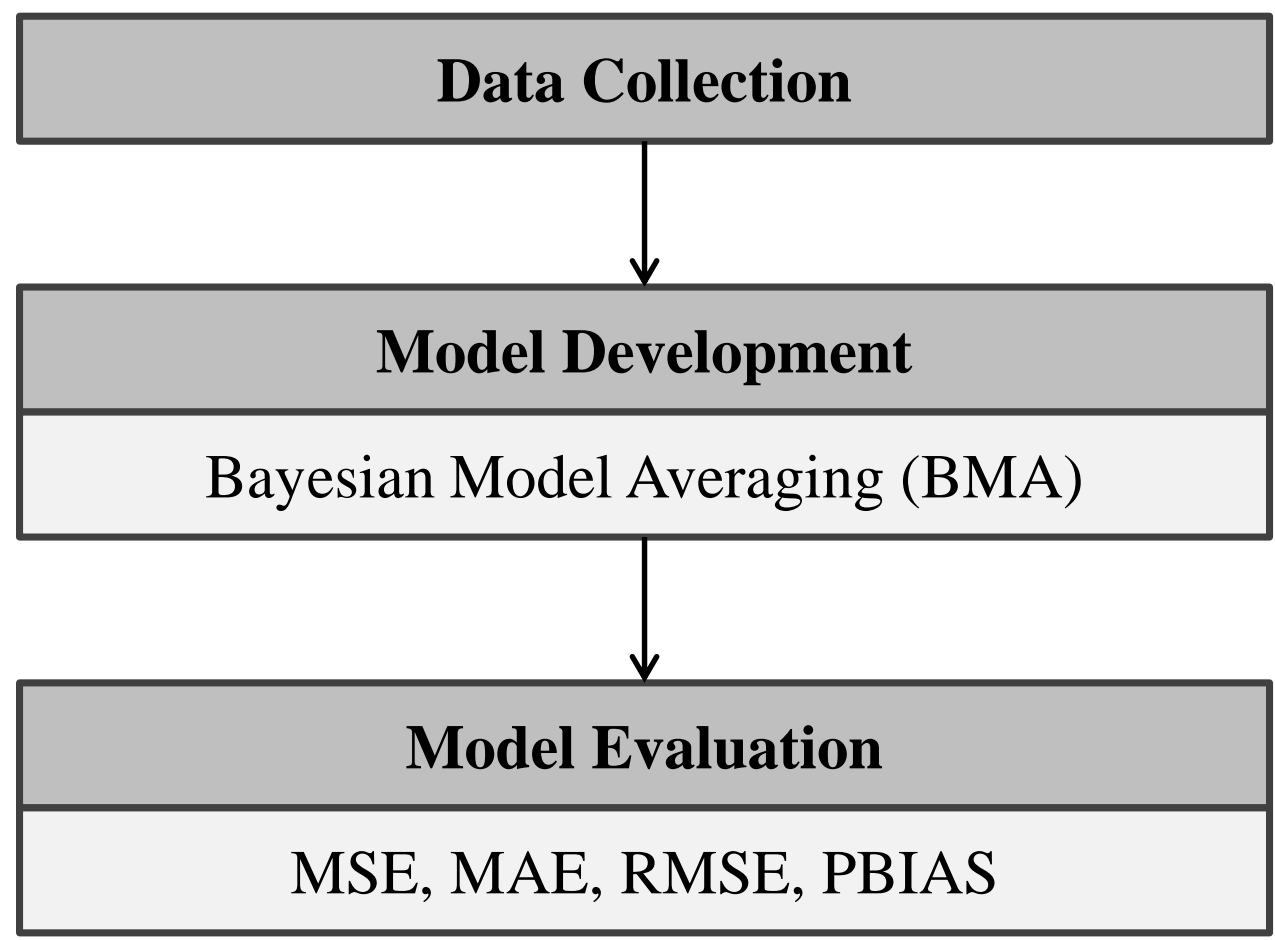



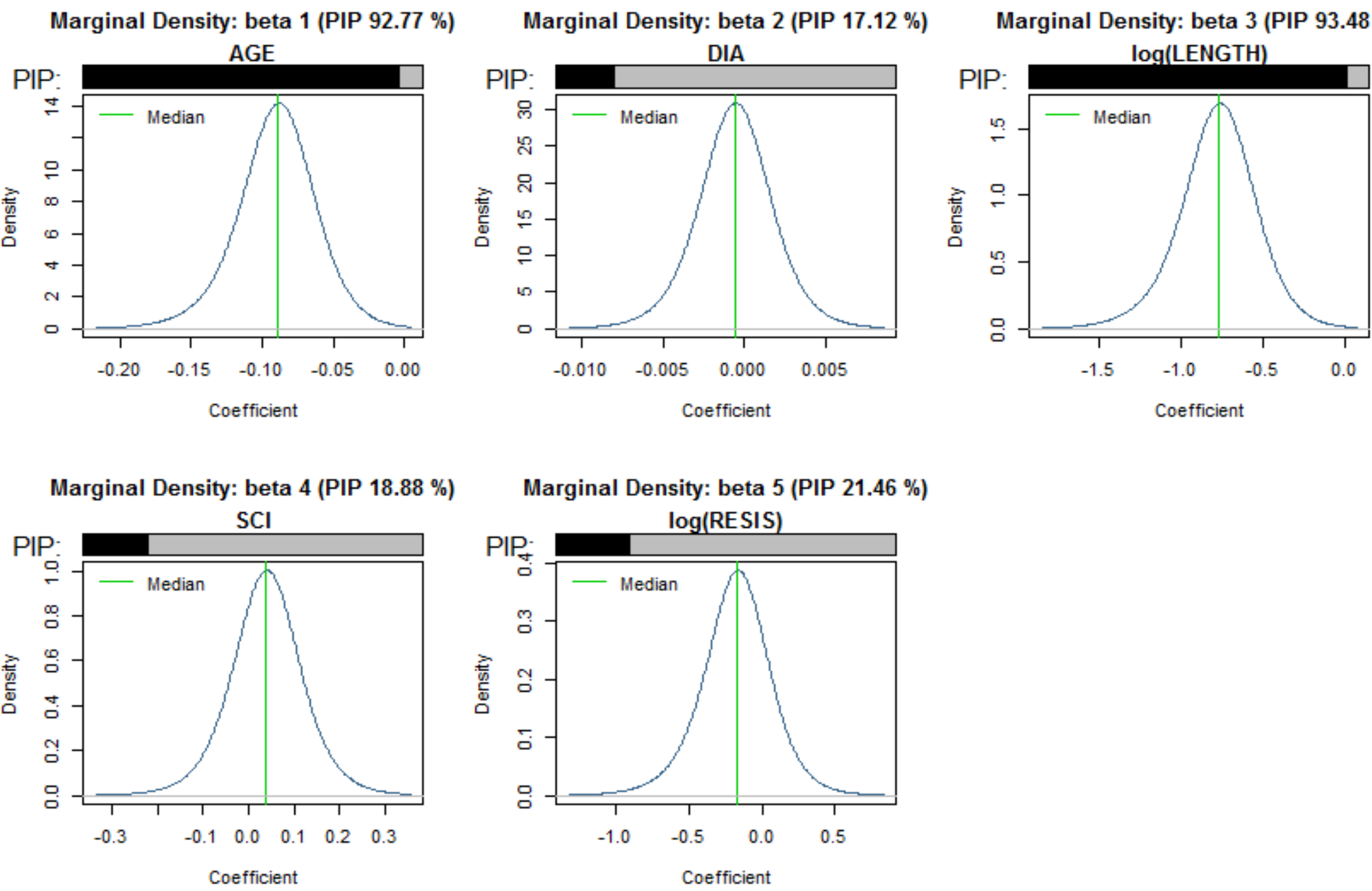

https://mc06.manuscriptcentral.com/cjce-pubs 